\title{
Short communication \\ Non-rainfall moisture inputs in the Knersvlakte: Methodology and preliminary findings
}

\author{
Roger Brown ${ }^{1 *}$, Anthony J Mills ${ }^{2}$ and Chris Jack ${ }^{1}$ \\ ${ }^{1}$ Climate System Analysis Group, EGS Department, University of Cape Town, Private Bag, Rondebosch 7701, South Africa \\ ${ }^{2}$ Department of Soil Science, Stellenbosch University, Private Bag X1, Matieland 7602, South Africa
}

\begin{abstract}
Dew, fog/mist and water vapour adsorption, the 3 vectors by which non-rainfall water can be added to soil water, may play a critical role in ecosystem function in arid zones. This paper explores a methodology for overcoming the challenges of measuring small daily inputs of non-rainfall water in the harsh environment of the Knersvlakte on the West Coast of South Africa. An automatic micro-lysimeter (MLS) - an experimental arrangement of a sensitive electro-mechanical load cell, suitable electronic amplification and signal conditioning, and a microcontroller was developed. A microcomputer was employed for overall system control and data logging. Initial field work took place between late September and November 2006 on Arizona Farm, 30 km north of Vanrhynsdorp. In March 2007, subsequent work began at the Ratelgat BIOTA observatory. Manual soil weight sampling corresponded well with theoretical dew maximums, with measured maximum and minimum dew/fog of $0.4 \mathrm{~mm}$ and $0.08 \mathrm{~mm}( \pm 0.08 \mathrm{~mm}$ ) (both in September 2006). Measurements from the first prototype MLS were marred by large $( \pm 0.24 \mathrm{~mm})$ error figures, signal dropout from the analog to digital converter, and insufficient range at the required resolution. The subsequent prototype (field tested in March 2007 and still in use) provides much smaller errors $( \pm 0.05 \mathrm{~mm}$ ). Calibration testing at Ratelgat indicates maximum overnight dew/fog contributions of $0.35 \mathrm{~mm}( \pm 0.05 \mathrm{~mm})$, which corresponds with theoretical calculations as well as field measurements in other arid zones. Maximum dew/fog derived soil water occurs between 07:00 and 09:15. Surprisingly, soil weight, as a consequence of dew/fog inputs, starts to increase shortly after 17:20. These are preliminary findings and longer term testing and validation are ongoing at present. The role of quartz pebbles and small succulent plants in the interception of non-rainfall water is still to be explored.
\end{abstract}

Keywords: non-rainfall water, dew, fog, micro-lysimeter, Knersvlakte, West Coast

\section{Introduction}

The abiotic drivers leading to the exceptional botanical diversity of the Knersvlakte (Cowling and Pierce, 2002), an arid plain strewn with quartz pebbles on the West Coast of South Africa, are elusive. Dew, fog and mist can play an important role in arid zone ecosystems, providing water to plants (Dawson, 1998), invertebrates (Seely et al., 2005), and soil microbes (Biederbeck et al., 1977). These water sources have not been quantified in the Knersvlakte, and in this study we consequently sought to:

- Quantify inputs of water into soil via dew, fog and mist

- Determine the duration of the wetting and drying periods.

The challenges of measuring non-rainfall water are numerous (Ninari and Berliner, 2002). Attempts to quantify small gains and losses of mass (as a consequence of added and lost soil water) relative to the bulk weight of the soil in highly mobile environments are beset with difficulties. Given the theoretical maximum dew quantity of $0.4 \mathrm{~mm}$ per night (Monteith and Unsworth, 1990), a minimum measurement resolution of less than $0.1 \mathrm{~mm}$ (of water) has been suggested for fog and dew studies (Agam and Berliner, 2006; Monteith and Unsworth, 1990). Such sensitivity is difficult to achieve given potential disturbances from inter alia wind, animals, rainfall, and drifting sand.

* To whom all correspondence should be addressed.

缅 +27 21 650-2748; fax: +27 21 650-5773;

e-mail: brown.roger@gmail.com

Received 9 November 2007; accepted in revised form 11 January 2008.
In this paper, we first explain the 3 vectors by which moisture from non-rainfall sources can be taken up by soil. Secondly we discuss the methodology employed in this study and finally we present and discuss the preliminary results.

\section{Non-rainfall systems of moisture input}

Three vectors (or pathways), discussed below, are recognised for the addition of non-rainfall water into the soil water, namely fog/mist deposition, dew formation and water vapour adsorption (Agam and Berliner, 2006). Mist is closely related to fog (small droplets of water suspended in the air with visibility in fog of less than $1 \mathrm{~km}$ and in mist less than $2 \mathrm{~km}$ ) and in this study no attempt was made to differentiate these two processes.

It is generally accepted that on the West Coast of South Africa advective fog is the dominant fog type (Olivier, 2002). This advective fog on the West Coast is a result of moist oceanic air advecting over the cold upwelling zone along the coast and then advecting inland. In addition cold land surfaces can cause fog to form along the coast. However, given the topography and abundance of quartz pebbles (possibly being an important factor in net cooling of the soil surface) in the Knersvlakte, radiation fog and inversion fog may well be an important contributor to soil water.

A key factor influencing dew deposition is the energy balance at the soil surface. Two dominant factors define the surface energy balance, namely net radiation and the energy flux arising from the wind. Net radiation $(\mathrm{Rn})$ is the sum of incoming and outgoing energy, and defined by three fluxes, soil heat flux $(\mathrm{G})$, sensible heat flux $(\mathrm{H})$ and latent heat flux (LE). The energy 
density $(G)$ used to heat the ground is a function of the thermal and hydraulic properties of the soil (Blight, 2002; Santanello and Friedl, 2003). The energy density $(\mathrm{H})$ is used to heat the air, and LE is the energy density exchanged in the evaporation/condensation of water. In arid environments, such as the study area, LE is thought to be the least dominant flux. During the day Rn can be generally assumed to be positive as incoming exceeds outgoing radiation, and the ground and air are being heated. However, beginning in the late afternoon and continuing until the following morning, particularly in soils with high albedo (whereby the late afternoon incoming solar radiation is reflected back into space), $\mathrm{G}$ reverses polarity and $\mathrm{R} n$ may become negative as the soil becomes an energy radiator rather than an energy sink (Monteith and Unsworth, 1990). The rate at which the transition between sink and radiator occurs is influenced in part by the relative magnitudes of the $\mathrm{G}$ and the $\mathrm{H}$. Soils with high $\mathrm{G}$ cool more rapidly than soils with lower $\mathrm{G}$ values. When the temperature at the surface has cooled to dew point temperature the possibility of nucleation of the liquid phase of water arises - i.e. commencement of dew formation (Agam and Berliner, 2006). Hence soils with high albedo and high $G$ values may reach dew point early in the day and therefore be more susceptible to dew formation.

Conversely, water vapour adsorption occurs when surface temperature exceeds dew point temperature and the relative humidity in the soil pores exceeds the relative humidity in the air. Two types of adsorption are recognised; physical and chemical. However, chemical adsorption is unlikely in soils (Hillel, 1998). Historically, water vapour adsorption has been discounted in arid zones as the relative humidity in soil pores was assumed to be very low as a consequence of lack of water in the system (Jacobs et al., 2002). However, this assumption is being questioned by authors such as Ninari and Berliner (2002) who found that despite the theoretical conditions for water adsorption not being met, water adsorption within an arid soil profile did occur. This has led to the speculation that in arid and semi-arid environments up to $20 \%$ of diurnal net radiation is latent-heat flux (the energy gained/lost in the transformation between liquid and vapour) (Agam and Berliner, 2006).

To date, arid-zone research has tended to 'silo' the 3 vectors (Jacobs et al., 2002, Sharan, 2007). The rationale behind this separation is that when conditions suitable for one phenomenon (dew, fog, or water vapour adsorption) exist, they theoretically preclude the occurrence of the other phenomena. In practice, however, separating dew formation and water vapour adsorption is fraught with difficulty. We consequently sought to measure changes in soil water derived from the various non-rainfall processes. Where an overnight soil water change exceeded the theoretical maximum for dew $(0.2$ to $0.4 \mathrm{~mm})$, for example, we made the assumption that one of the other processes, at some stage during the late afternoon, overnight, and/or early morning, contributed to soil water.

Given the very low theoretical level of dew and the paucity of information available on the deposition of fog in the Knersvlatke, this study applied the microlysimeter (MLS) model as described by Heusinkveld et al. (2006). The MLS is, in essence, a scale balance buried below-ground with the weighing platform (in this case, a dish) approximately $5 \mathrm{~mm}$ above the level of the soil surface. The design is such that the soil in the dish is exposed to the same environmental changes as the surrounding soil mass but should not receive additional weight from the addition of wind-blown soil particles. The soil within the dish is isolated from capillary rise action and from overnight distillation, processes whereby water is added to the soil surface from below (Francis et al., 2007). This isolation ensures that the only water vectors are those from above. It is assumed that weight changes of the soil sample (after a settlement period) reflect the gains and losses of soil water derived from vectors described above.

The MLS methodology is suitable for distinguishing between rainfall and non-rainfall events. A rainfall event causes a sudden increase in soil weight producing a noticeable spike in output from the load cell. Differentiating fog and dew is, by contrast, difficult. The time of day of maximum soil water does, however, provide clues as to which process has contributed to soil water on any given day. Physical disturbance is also able to be resolved in the data analysis process as disturbance produces obvious changes to the daily cycle of wetting and drying.

Ninari and Berliner (2002) suggested a limitation of the MLS methodology whereby the temperature profile of the soil within the soil dish is probably not the same as that within an undisturbed soil mass of the same dimensions. However, Heusinkveld et al. (2006) noted that their results showed no difference between a 30 and $75 \mathrm{~mm}$ deep soil dish. Following Heusinkveld et al. (2006), this study assumes that a $35 \mathrm{~mm}$ deep soil dish will provide a sufficient enough temperature gradient to reflect the surface energy balance and the non-rainfall water interception characteristics of undisturbed soil.

\section{Experimental}

\section{The MLS - specifications and design}

The MLS methodology employed in this study uses the changing weight of a soil sample to determine the quantity and residence time of soil water derived from non-rainfall water. Because no standard exists for the construction of MLSs we employed an experimental arrangement of load cell, amplification and datalogger. A soil-sample dish $(d=88 \mathrm{~mm}, h=35 \mathrm{~mm})$ was supported $250 \mathrm{~mm}$ above the load cell. The Wheatstone bridge in the load cell is deformed by changes in weight in the soil-sample dish. When direct current voltage is supplied, this deformation causes a change in electrical resistance across the bridge and therefore a change in voltage out.

Excitation of the Teadea-Huntleigh 1004 (300g) load cell, chosen for this study, with $10 \mathrm{~V}$ DC produces a maximum output of 8.6 milliVolts $(\mathrm{mV})$, which is equivalent to $0.029 \mathrm{mV} \cdot \mathrm{g}^{-1}$. Given a required minimum resolution of $0.1 \mathrm{~mm}(0.61 \mathrm{~g})$ of water added to or lost from the soil-sample dish, the output or signal change to be detected would be $0.02 \mathrm{mV}$.

Given this very low change in signal, two amplification alternatives present themselves, namely to passively increase the magnitude of the weight change by changing the dimensions of the soil-sample dish, or to use electronic amplification. The downside of passive amplification is the increase in 'dead weight' (being the bulk weight of the soil in the dish). Such an increase would require the use of a load cell with a greater fullscale weight which may create another problem in that the signal (caused by the weight change) becomes equivalent to the total error of the load cell. The alternative approach, namely electronic amplification creates different problems relating to power supply requirements and electronic drift and noise. In addition, it should be noted here that harsh arid environments are not as conducive to the use of high-gain electronic equipment as is an environmentally controlled or buffered indoor environment.

In this study, we decided to employ minimum passive amplification; therefore high levels of electronic amplification were used to achieve the required weight change resolution.

The first MLS prototype employed a 0 to $2.5 \mathrm{~V} 12$ bit ana$\log$ to digital converter; however, laboratory and field testing 


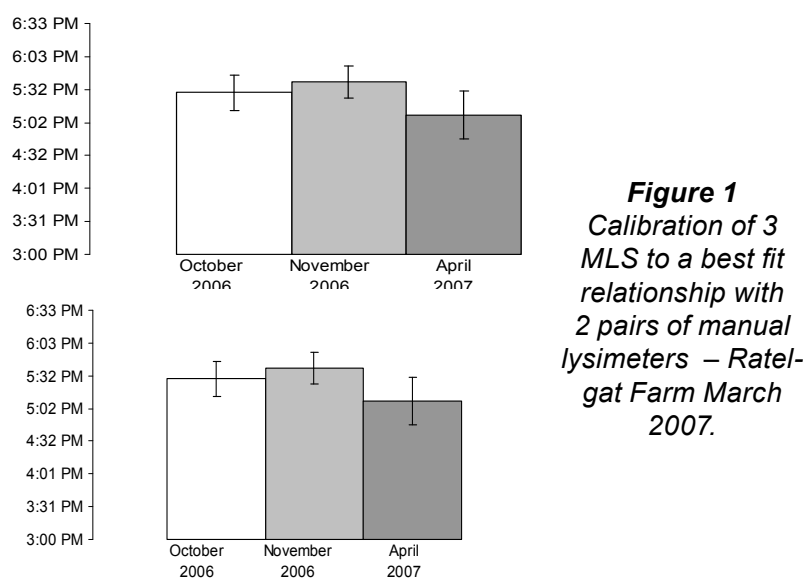

showed that this model had a problem in the field whereby the signal would 'drop out' inexplicably. Furthermore the 0 to $2.5 \mathrm{~V}$ range was insufficient for the level of amplification required. In the subsequent prototype a 10 bit microcontroller with improved sampling rates, control and voltage range was employed. A lowpower microcomputer was then employed for overall system control and data logging.

Both prototypes were calibrated in the laboratory and then in the field. In the field four manual lysimeters were used $(d=70$ $\mathrm{mm} h=35 \mathrm{~mm}$ ) with weights (using a UWE JW-2500 scale, UWE, Taiwan) taken 3 times during the day. The load cell was supplied with power every $10 \mathrm{~min}$ and the mean of 30 (initially, and 250 subsequently) sample soil weights was taken.

\section{Errors}

To validate the calibration process a standard weight was used to assess the accuracy of the JW2500 scale as the internal battery discharged. It was found that as the scale battery discharged the standard weight changed by $0.1 \mathrm{~g}(0.025 \mathrm{~mm}$ of water). In addition the variation between the 4 manual readings $( \pm 0.06 \mathrm{~mm})$ indicates that a total error of $0.08 \mathrm{~mm}$ of water should be applied to the manual lysimeters weights.

The MLSs were calibrated in the laboratory to determine the voltage change per gram weight added. This calibration was refined in the field test by contrasting MLS figures with those of the manual lysimeters, whereby the MLS results were adjusted to match a given manual reading, such that for the calibration period the MLS results provided a 'best fit' relationship with the manual readings (see Fig. 1). Figure 1 shows this 'best fit' relationship of 3 MLSs against 2 sets (with duplication in each set) of manual lysimeters over $5 \mathrm{~d}$. Two subsequent days are also shown to demonstrate the duplication of the MLS results.

\section{Results and discussion}

\section{Field site tests}

The $1^{\text {st }}$ prototype was installed at Arizona Farm (31 18 47.5S, $183833.0 \mathrm{E}$ ) for $50 \mathrm{~d}$ between late September and November in 2006. The $2^{\text {nd }}$ prototype was installed at Ratelgat Farm (31 17 23.3S, 1835 52.2E) in March 2007 and continued for a period of 25 d into April 2007.

\section{Field-Test 1: Arizona Farm}

The maximum non-correctable difference between a manual weight (in $\mathrm{mm}$ ) and the MLS derived weight, for the first pro-

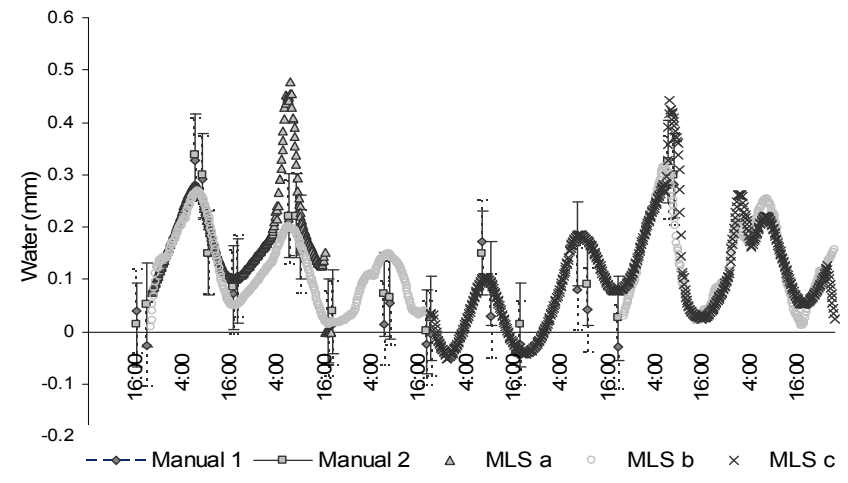

Figure 2

Time at minimum (left) and time of maximum soil water (right). The plots demonstrate that the soil remains moistened by nonrainfall water for the majority of day-light hours, and that further moistening generally commences before sunset.

totype, was $0.24 \mathrm{~mm}$. This large (in relation to theoretical dew maximums and measured dew/fog quantities) error made the absolute quantity data derived from the MLS in this field test unreliable; however, daily trend and duration measurements still provide useful information.

Manual readings taken during the calibration period in late September 2007 indicate $0.08 \mathrm{~mm}, 0.22 \mathrm{~mm}$ and $0.40 \mathrm{~mm}$ were minimum, average and maximum respectively, water added to the soil from non-rainfall vectors. In a $50 \mathrm{~d}$ period, post-calibration, MLS derived figures show a maximum overnight soilwater addition of $0.53( \pm 0.24) \mathrm{mm}$ and a minimum of $0.21( \pm$ $0.24) \mathrm{mm}$. Excluding those days where the output demonstrated a rainfall event, an overnight average $0.426( \pm 0.24) \mathrm{mm}$ of nonrainfall derived soil water was recorded. The maximum recorded addition may have been a result of a fog event; however, given the significant error; it is problematic to definitively attribute the result to fog. Although, given that this overnight addition of water is considerably greater than other results in the same time period we suggest that a fog event may have occurred. In addition, given the geographical distance of this field site from the West Coast further work is needed distinguish moisture from advective and/or radiation/inversion fog.

Non-rainfall results from October indicate that mean minimum soil water (in the soil-sample dish) occurred at 17:30. Mean maximum soil water occurred at 8:42 am (see Fig. 1). Time of minimum soil water in November occurred in a slightly tighter time band than in October; with minimum mean weight recorded at 5:40 pm. Mean maximum soil water occurred at 7:48 am. The times of minimum and maximum soil water indicate that despite the low quantity of water added to the soil the soil remains moist for a considerable duration. This finding challenges any preconceptions that the duration of non-rainfall water in the soil is short.

Drying trends, expected at this time of year, are not evident in the results. Any trend may be camouflaged by the significant error figures, noted previously, or the relatively constant level of overnight water accumulation.

\section{Field-Test 2: Ratelgat}

The changes to the sampling rates, signal amplification and conditioning circuitry significantly reduced the difference between manual samples and MLS output to less than the manual sample error $(0.08 \mathrm{~mm})$. Hence quantity results for March 2007 are significantly more robust than those for October and November 2006. 


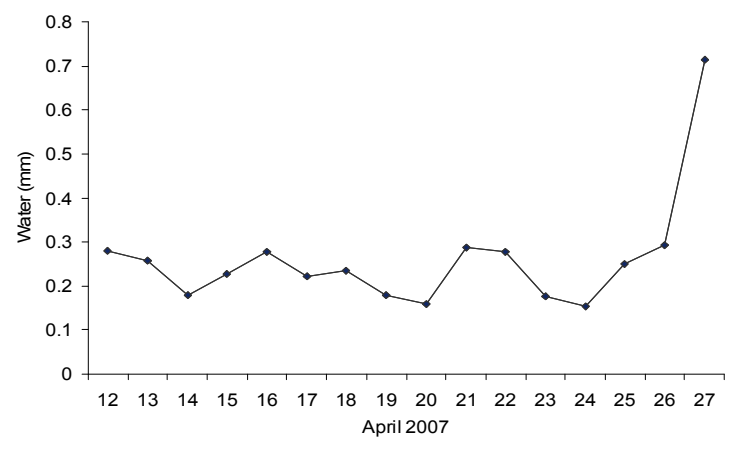

Figure 3

Overnight moisture trends - Ratelgat Farm 12-27 April

This increased accuracy is reflected in field-test calibrations. The maximum manual reading taken during the field calibration of the second prototype MLS was $0.35 \mathrm{~mm}$ (see Fig. 3). The average overnight water increase in the 5 manual lysimeters was $0.18 \mathrm{~mm}$ while the MLS-derived increase was $0.2 \mathrm{~mm}$. The $14 \mathrm{~d}$ following the calibration period also indicated that the average overnight soil water derived from non-rainfall sources was 0.23 $( \pm 0.08) \mathrm{mm}$ (see Fig. 3). These results do not suggest that a fog event occurred during this time period.

March 2007 showed a greater standard error in the time of minimum and maximum soil water than October and November 2006 (22 $\mathrm{min}$ and $18 \mathrm{~min}$, compared to $15 \mathrm{~min}$ (for October and November) and 11 and $13 \mathrm{~min}$ respectively). However, the time of minimum soil water is statistically the same $(F=0.6551 p=$ 0.52 ) across the 3 test periods. There is a statistical difference $(\mathrm{F}=6.48 \mathrm{p}=0.0033)$ between time of maximum soil moisture. A post-hoc Tukey HSD test showed a significant difference between time at maximum soil water between November 2006 and March 2007 ( $p>0.01$ ); all other comparisons were statistically insignificant. There was homogeneity of variance in the data across the 3 test periods and no data transformation was required. A rainfall event was detected at the end of the measurement period (see Fig. 3)

The most notable outcomes from these preliminary results are:

- Moisture is being accumulated in the soil from approximately 17:30

- The soil reaches its maximum water content between about 07:00 and 09:00

- The moisture accumulated in the soil falls within the theoretical parameters for dew.

\section{Conclusions}

These preliminary results show that the soil contained in the sample dish of the MLS, isolated from moisture recharge from below, follows a daily pattern of wetting and drying. The results suggest that dew formation and water vapour adsorption are taking place in the Knersvlakte. There was no conclusive evidence of fog (the $3^{\text {rd }}$ vector under consideration in this study) events in these preliminary results. The lack of evidence of fog is surprising given the perception that the region is regarded as being prone to fog. In the next phase of this study, we will seek to isolate the different non-rainwater vectors.

The small amount of water added to the soil $( \pm 0.2 \mathrm{~mm}$ per night) from non-rainfall sources, in combination with a high temperature environment, may lead to an expectation that the duration that the soil remains moist, from non-rainfall water, would be short. However, a surprising outcome from these pre- liminary results is that soil retains moisture from non-rainfall inputs through most of the day, and that it begins to accumulate further water prior to sunset. The extent to which the soil properties and the abundance of quartz pebbles in the Knersvlakte makes this wetting in the late afternoon possible is still to be fully explored. The findings reported here indicate that over a year, non-rainfall may contribute up to $70 \mathrm{~mm}$ of water (or nearly $60 \%$ of mean annual rainfall - relative to 6 - year levels from the Ratelgat BIOTA observatory) to the system. Ongoing research is exploring whether the presence and the morphology of succulent species influences the interception of non-rainfall water.

These findings, while preliminary in nature, offer a first glimpse into the previously unexplored non-rainfall water vectors in the Knersvlakte.

\section{Acknowledgements}

This research was supported by a grant from the Department of Science and Technology as an extension to BIOTA Southern Africa (sponsored by the German Federal Ministry of Education and Research under promotion number 01 LC 0024A). The authors wish to thank Cape Nature for the use of Arizona Farm, the Griqua Development Trust for access to Ratelgat Farm. In addition we would like to thank Professor Bruce Hewitson, Associate Professor Robert Tait, Mr Samuel Ginsberg, and Mr Glen Newis all at the University of Cape Town.

\section{References}

AGAM N and BERLINER P (2006) Dew formation and water vapour adsorption in semi-arid environment - A review. J. Arid Environ. (65) $572-590$

BIEDERBECK V, CAMPBELL C and NICHOLAICHUK W (1977) Simulated dew formation and microbial growth in soil of a semiarid region of western Canada. Can. J. Soil Sci. 57 93-102.

BLIGHT G (2002) Measuring evaporation from soil surfaces for environmental and geotechnical purposes. Water SA 28 (4) 381-394.

COWLING R and PIERCE S (2002) Namaqualand: A Succulent Desert. Fernwood Press, Cape Town, South Africa.

DAWSON T (1998) Fog in California redwood forest: Ecosystem inputs and use by plants. Oecologia 117 476-485.

FRANCIS M, FEY M, PRINSLOO H, ELLIS F, MILLS A and MEDINSKI T (2007) Soils of Namaqualand: Compensations for aridity. J. Arid Environ. 70 (4) 588-603.

HEUSINKVELD B, BERKOWICZ S, JACOBS A, HOLTSAG A and HILLEN W (2006) An automated microlysimeter to study dew formation and evaporation in arid and semiarid regions. Am. Meteorol. Soc. 7 825-831.

HILlEL D (1998) Environmental Soil Physics., Academic Press, San Diego, USA.

JACOBS A, HEUSINKVELD B and BERKOWICZ S (2002) A simple model for potential dewfall in an arid region. Atmos. Res. (64) 285-295.

MONTEITH J and UNSWORTH M (1990) Principles of Environmental Physics. Routledge New York, USA.

NINARI N and BERLINER P (2002) The role of dew in the water and heat balance of bare loess soil in the Negev Desert: Quantifying the actual dew deposition on the soil surface. Atmos. Res. (64) 323-334.

OLIVIER J (2002) Fog-water harvesting along the West Coast of South Africa: A feasibility study. Water SA 28 (4) 349-360.

SANTANELLO J and FRIEDL M (2003) Diurnal covariation in soil heat flux and net radiation. J. Appl. Meteorol. 42 (6) 851-862.

SEELY M, HENSCHEL J and HAMILTON W (2005) Long-term data how behavioural fog adaptations determine Namib Desert beetle abundance. S. Afr. J. Sci. 101 (11/12) 570-572.

SHARAN G, BEYSENS D and MILIMOUK-MELNYTCHOUK I (2007) A study of dew water yields on galvanised iron roofs in Kothara (north-west India). J. Arid Environ. (69) 259-269. 